\title{
Bacteriological and Molecular Detection of Methicillin-resistant Staphylococcus Aureus Isolated From Cigarette and Hookah Smokers in Khartoum State
}

\section{Jara Osman Ali Osman}

Sudan University of Science and Technology

\section{Esraa abdulraman Abdallah Bakri}

Sudan University of Science and Technology

Ahmed Ibahim Hashim

Sudan University of Science and Technology

Ahmed Bakheet Abd Alla ( $\nabla$ ahmed.hassanab@gmail.com )

Sudan University of Science and Technology _ College of Medical Laboratory Science

https://orcid.org/0000-0002-5463-9892

Hisham N Altayb

King Abdulaziz University

\section{Yousif Fadlallah Hamedenil}

Sudan University of Science and Technology college of medical laboatory science

\section{Research note}

Keywords: Antibiotic, Staphylococcus aureus, Bacteriology

Posted Date: July 8th, 2020

DOI: https://doi.org/10.21203/rs.3.rs-38865/v1

License: (a) (i) This work is licensed under a Creative Commons Attribution 4.0 International License. Read Full License 


\section{Abstract \\ Objective}

Staphylococcus aureus is an extra-ordinarily versatile pathogen that causes a wide variety of infections in humans and animals, capable of causing superficial lesions and systemic infections. The aim of this study was to detect mecA gene in smokers of cigarette and hookah.

\section{Results}

Forty-one isolates (41\%) were identified as $S$. aureus by traditional culture methods. non-smokers, nasal carriers of $S$. aureus were $16(39 \%)$ while $25(60 \%)$ among smokers $(P=0.103)$. Of the overall 25 smoker nasal carriers, 18 were hookah smokers and 7 were cigarettes smokers $(P=0.004)$. MRSA was $1(2.4 \%)$ in non-smokers and $3(7.2 \%)$ in smokers, 2 in cigarettes and 1 in hookah $(P=0.009)$. Only 38 isolates were confirmed as $S$. aureus by PCR (mecA gene). In non-smokers group mecA were 6 (15.8\%) positive and 8 $(21 \%)$ negative, while in smokers were $16(42.3 \%)$ positive and $8(20.9 \%)$ negative isolates $(P=0.187)$. From hookah 12 mecA positive and 4 from cigarette $(P=0.647)$. The correlation of MRSA and using of antibiotic during last 6 months indicates significant $(P=0.031)$.

\section{Introduction}

Cigarette smoking (CS) is the leading preventable cause of death, disease, and disability worldwide. In 2010, nearly 6 million worldwide deaths were due to cigarette smoking and second-hand exposure. Forty percent of children worldwide regularly exposed to second- hand cigarette smoke [1-3].

Both direct and second-hand cigarette smoke exposures increase the risk and severity of developing respiratory tract and other invasive infections [4]. Invasive pneumococcal disease is $2-4$ folds more common in cigarette smokers, in addition to influenza and tuberculosis infections [2,5]. CS exposure can impair epithelial innate immune responses to microbial products, perhaps setting the stage for overgrowth and invasion [1, 4]. Adverse health effects linked to cigarette smoke, including carcinogenesis [4], and chronic pulmonary disease, are commonly believed to arise from the direct action of tobacco smoke components on human cells [2]. CS contains a variety of bioactive substances, including oxidizing, genotoxic, and immunomodulatory factors $[7,8]$. Exposure to cigarette smoke raises the risk of many infectious diseases $[9,10]$. Kulkarni and his colleagues demonstrated that CS can impair epithelial innate immune reactions to microbial products [11]. Perhaps setting the stage for overcrowding and invasion [9]. Invasive pneumococcal disease is 2-4 times more common among cigarette smokers, in addition to influenza and tuberculosis infections [12]. Moreover, direct and second-hand cigarette smoke exposures change the normal composition of the nasopharyngeal microflora, opening the door to opportunistic pathogens such as S. aureus, Haemophilus influenzae, and Streptococcus pneumoniae $[5,12]$. 
Tobacco in hookahs is exposed to high heat from burning carbon dioxide, and smoke is at least as toxic as cigarette smoke, this could lead to absorption of more toxic substances than those absorbed by cigarette smokers [13].

The amount of smoke inhaled during a typical hookah session is about 90,000 millilitres ( $\mathrm{ml})$, compared with $500-600 \mathrm{ml}$ inhaled when smoking a cigarette [14].

Hookah smokers can be at risk for some of the same problems as cigarette smokers [5]. These include oral cancer, prostate cancer, stomach cancer, oesophageal cancer, diminished lung function and decreased fertility [15].

S. aureus is Gram-positive cocci that causes a broad range of infections, including pneumonia, bacteraemia, and endocarditis $[5,15]$. Methicillin Resistant $S$. aureus (MRSA) is resistant to oxacillin, methicillin and all beta lactam agent [16]. Smokers have high rates of MRSA colonization than nonsmokers, thus increasing risk of serious and difficult to treat infections [17]. The primary mechanism for this resistance is the production of an altered Penicillin Binding Protein 2a (PBP 2a). MRSA produces a PBP 2a mediated through the mecA gene, MRSA has a higher mortality rate for bacterial infections than for methicillin-sensitive $S$. aureus (MSSA) $[17,18]$. On the other hand, cigarette smoking promotes bacterial virulence, since the colonizing microbiota inhabits human mucosal spaces, microbes that share exposure to a variety of environmental stimuli, including CS $[11,19]$. Durmaz and his colleagues believed that exposure of $S$. aureus to smoking could lead to pathways for survival against antimicrobial activity [20]. Smokers have elevated levels of MRSA colonisation relative to non-smokers, raising their risk of severe and difficult infections to treat $[11,20]$. Smokers with acute and chronic sinusitis have a high prevalence of $S$. aureus and MRSA as pathogens relative to non-smokers $[5,11,21]$.

Staphylococci grow well aerobically and in a carbon dioxide enriched atmosphere [22]. MRSA strains can be identified using a latex agglutination test kit [23].

MRSA was treated by vancomycin [24], but recently uses antibiotic such as linezolid, daptomycin and mupirocin $[25,26]$.

\section{Methods}

\section{Methods}

This was case-control study, conducted in Khartoum state from 15th January to the 30th of July 2018.

Participant of this study were males of age from 20 to 65 years old. Fifty adult males who smoke cigarette or hookah as case, another fifty non-smokers males as control were enrolled in this study. The case divided into two groups, twenty-five were cigarette smokers and the others were hookah smokers, participants under treatment or immunocompromised were excluded from study. 
Samples were collected based on probability convenience technique, then data were collected by direct non-self -constricting questionnaire from participant.

\section{Specimens Collection}

The specimens were collected from anterior nares by using sterile cotton swab emulsified by peptone water, collection was done by inserting the swab and gently rotating for several times, collected specimens were labelled by number, packaged and processed within one hour of collection to Microbiology Laboratory in Sudan University of Science and Technology.

Each nasal swab inoculated into peptone water and incubated aerobically at 37Co for 24 hours then inoculated by using sterile loop into Mannitol Salt Agar (MSA) and incubated aerobically at 37Co for overnight. After incubation, isolates show significant growth were identified using standard microbiological methods, which included colonial morphology, Gram's stain, biochemical tests and molecular techniques (PCR).

\section{Bacterial Identification}

Colonies were examined in the next day. The organisms were identified according to the morphology of the colonies, Gram stain [27], biochemical tests and gene detection for the 16 s RNA of S. aureus.

\section{In-vitro Antibiotic Sensitivity Testing}

Kirby-Bauer method was used in the current study; the antibiotic discs used were from $\mathrm{HI}$ media (HI media Laboratories Pvt. Ltd, Mumbai 400086, India). The Oxacillin antibiotic (10 mg) and Vancomycin (30 mg) were used. The discs of the antibiotics placed in the diagnostic susceptibility test agar (Muller Hinton Agar). The distance between the two adjacent discs was at least $20 \mathrm{~mm}$ and from the edge of the plate was $15 \mathrm{~mm}$. The media were incubated aerobically for 24 hours in $37^{\circ} \mathrm{C}$. After 24 hours of incubation, the diameter of the zone inhibition was measured and compared with the published tables of the control strains according to Clinical Labratorey Stander Institute guidelines (CLSI)[28]. The results were compared with S. aureus control ATCC 25923.

Genotyping of Staphylococcus aureus resistant genes

DNA was extracted by boiling method [29], by tacking small inoculums of bacteria cultured on nutrient agar, dissolving it in $0.5 \mathrm{ml}$ of D.W in $1.5 \mathrm{ml}$ Eppendorf tube and $10 \mathrm{ml}$ of proteinase $\mathrm{K}$ was added for overnight at $37 \mathrm{C}^{\circ}$, then boiled for 20 minutes, then incubated in refrigerator at -20 for 10 minutes. Repeated this process four times (heat shock), then centrifuged at $12000 \mathrm{rpm}$ for $5 \mathrm{~min}$. The supernatant used as template DNA for PCR. 
The multiplex PCR was done by using a thermo-cycler (techne 312, England). The primer in table (1) [30], the following conditions: denaturation at $94 \mathrm{Co}$ for 10 minutes, followed by 10 cycles of denaturation at 94Co for 45 seconds, annealing at $55 \mathrm{Co}$ for 45 seconds, and extension at $72 \mathrm{Co}$ for 75 seconds. Moreover, another 25 cycles of $94 \mathrm{Co}$ for 45 seconds, $50 \mathrm{Co}$ for 45 seconds, 72 Co for 45 seconds, and a final extension step at $72 \mathrm{Co}$ for 10 minutes.

The Amplicon were separated at 120 Volt for $15 \mathrm{~min}$ in $1.5 \%(\mathrm{w} / \mathrm{v})$ agarose gel containing ethidium bromide, bands were visualized under U.V trans-illuminator (UVitec - UK) to detect the specific amplified products by comparing with 50 base pairs standard ladders (INtRON biotechnology. Korea). All samples were confirmed as $S$. aureus by specific housekeeping gene primer (16 s RNA), negative sample were excluded.

\section{Statistical analysis}

Data were analysed using SPSS version-20. The Chi-squared test was performed to determine bivariate correlation and statistical significance and a $P$-value of less than 0.05 was considered statistically significant.

\section{Results}

\section{Phenotypic analysis}

S. aureus were found in the nasal of smokers 7 (17.1) and 18 (43.9) in Ciggrate and Hookahs respectively and non-smokers 16 (39) with insignificant association (P.value $=0.103)$. The distribution of $S$. aureus in cigarette and hookah smokers and it was very high in hookah smokers, $7(28 \%)$ and 18 (72\%) respectively. There was association between hookah and nasal carriers $(P=0.000)$.

S. aureus was susceptible to Vancomycin (41 were sensitive). In this study four participants from total number of $S$. aureus carriers were MRSA, while 35 carriers were MSSA and (2) isolates were showed intermediate result.

MRSA presence was higher in cigarette smokers than in hookah ( 2 folds), while only one case of MRSA was found in non-smokers as showed in Table 2. 
Table 1

Nucleotide sequences of the primers used in the Multiplex PCR for the simultaneous detection of $16 \mathrm{~s}$ rRNA gene, and the mecA gene.

\begin{tabular}{|llll|}
\hline Primer name & DNA sequence (5to 3) & Ampilicon size (bp) & Specificity \\
\hline MecA1 - F & 5- AАСTCTGTTATTAGGGAAGAACA-3 & 310 bp & MecA \\
MecA1 - R & 5- CСАCCTTCCTCCGGTTTGTCACC-3 & & \\
\hline Staph 756- F & 5- AACTCTGTTATTAGGGAAGAACA-3 & 756 bp & 16S rRNA \\
Staph 750- R & 5- ССАCCTTCCTCCGGTTTGTCACC-3 & & \\
\hline
\end{tabular}

Table 2

Distribution of Staphylococcus aureus, susceptibility test and Mec A gene among study group.

\begin{tabular}{|c|c|c|c|c|c|}
\hline \multirow[t]{3}{*}{ Variable } & \multirow{2}{*}{\multicolumn{3}{|c|}{$\begin{array}{l}\text { Smoker } \\
(\%)\end{array}$}} & \multirow{3}{*}{$\begin{array}{l}\text { Non smoker } \\
\text { (\%) }\end{array}$} & \multirow[t]{3}{*}{ Total } \\
\hline & & & & & \\
\hline & Ciggrate & Hookahs & P.value & & \\
\hline Frequency & $7(17.1)$ & $18(43.9)$ & 0.004 & $16(39)$ & $41(100)$ \\
\hline \multicolumn{6}{|l|}{ Staphylococcus aureus } \\
\hline Susceptibility test & $5(12.2)$ & $16(39)$ & 0.009 & $14(34.1)$ & $41(100)$ \\
\hline Oxacillin & $0(0)$ & $1(2.4)$ & & $1(2.4)$ & \\
\hline 1- MSSA & $2(4.8)$ & $1(2.4)$ & & $1(2.4)$ & \\
\hline \multicolumn{6}{|l|}{ 2- Intermediate } \\
\hline \multicolumn{6}{|l|}{ 3- MRSA } \\
\hline \multicolumn{6}{|l|}{ Vancomycin } \\
\hline Mec A gene & $4(10.7 \%)$ & $12(31.6)$ & 0.647 & $6(15.8)$ & $38(100)$ \\
\hline Positive & $3(7.9)$ & $5(13)$ & & $8(21)$ & \\
\hline Negative & & & & & \\
\hline
\end{tabular}

The relationship between nasal carriers of $S$. aureus and smokers group indicated significant relationship $(P=0.001)$, Moreover, the relationship between nasal carriers and number of cigarette or hookah per day indicated significant $(P=0.008)$, while, the relationship between nasal carriers and smoking years indicated insignificant $(P=0.479)$.

\section{Genotypic Analysis}


Forty one isolate of $S$. aureus were examined by the multiplex PCR to detect the presence of $16 \mathrm{~s} r \mathrm{rNA}$ and mecA gene (Fig. 1), three samples were negative to $16 \mathrm{~s}$ rRNA, so were excluded from the study, and mecA was detected in the remainder 38 isolates.

From (38) $S$. aureus isolates (22) were MRSA positive, which was observed to be higher in smokers than non-smokers (16 and 6) respectively as showed in Table 2.

\section{Discussion}

In all nasal swabs, the phenotypic confirmation of $S$. aureus was performed using culture methods. The total number of confirmed $S$. aureus isolates was 41 . Smoking carriers were $25(61 \%)$, this finding differs from that reported by Durmaz et al. (2001) [20] Who was found (33\%) and Abdullah et al. (2010) [31] who was found (22\%). While there were $16(39 \%)$ S. aureus isolates in non-smokers carriers, which was slightly near to the result obtained by Chattergee, (2009) [32] who was found (30\%) and Lu et al. (2005) [33] who was found (32\%).

These findings indicate a substantial rise in $S$. aureus in the smoker group rather than the non-smoker group. The distribution of $S$. aureus among smokers' group $(n=25)$ was: hookah group $18(72 \%)$ while in cigarette $7(28 \%)$, this result has shown an increase in the colonization of $S$. aureus in the hookah group more than a cigarette; this may be due to an increase in inhalation of more than a cigarette in the hookah, it may also be due to the sharing of hookah devices between different personnel, which may increase the colonization of $S$. aureus in this group.

In smokers $3(7.3 \%)$ MRSA were found (2 (4.2\%) from cigarette and 1 (2.4\%) from hookah), this finding closed to Durmaz et al. (2001) [20] who was found (6\%). In other hand MRSA in non-

smoker was only one isolate (2.4\%), this finding was lower from reported by Abdallah et al. (2010) [31] who was found (4\%). This phenotypic analysis shows that the cigarette increases the resistance of $S$. aureus more than the hookah.

There was significant association between nasal carriage and smoking (P. value $=0.001)$, and number of smoking per day $(P$. value $=0.008)$, this means that, smoking increases the colonization of $S$. aureus by smoking per day $(P$. value $=0.479)$.

This study revealed $6(15.8 \%)$ isolates were mecA positive from non smoker, while there were $16(42.3 \%)$ $S$. aureus in smokers. This genotypic analysis removes 3 phenotypically reported samples as $S$. aureus, which indicates that it is more accurate than phenotypic analysis. In addition, genotypic study reveals a sharp rise in Oxacillin resistant to more than phenotypic study, because of its ability to identify an unexpressed gene, it is an innovative diagnostic method and more efficient than a phenotypic study. In addition, the genotypic study revealed a higher concentration of mecA in the hookah than the cigarette according to the phenotypic study; This may increase the amount of nicotine and inhaled smoke in the hookah by more than a cigarette due to the presence of toxic substance in the hookah. Furthermore, the 
way in which genes are transmitted (through plasmid) and the way in which hookah is used (different people share one device) helps to spread the mecA gene between different $S$. aureus carriers.

\section{Conclusion}

Smoking show significant association with nasal colonization of $S$. aureus. There was a high rate of MRSA nasal carriage in hookah group. Hookah smoking consider as strong risk factor for MRSA colonization.

\section{Limitations}

- Only male were included in this study.

- Low sample size due to financial issues

\section{Abbreviations}

\section{MRSA}

Methicillin Resistant $S$. aureus

PCR

polymerase chain reaction

CS

Cigarette smoking

$\mathrm{ml}$

millilitres

PBP 2a

Penicillin Binding Protein 2a

MSSA

methicillin-sensitive $S$. aureus

MSA

Mannitol Salt Agar

rRNA

ribosomal ribonucleic acid

CLSI

Clinical Labratorey Stander Institute

DNA

deoxyribonuclease

D.W

distilled water

Rpm

rotate per minute

$\mathrm{w} / \mathrm{v}$ 
weight / volume

U.V

ultra violet

SPSS

Statistical Package for the Social Sciences

MLS - IEC

Committee of medical laboratory science -ethical approval number

\section{Declarations}

\section{Ethics approval and consent to participate}

Ethical clearance for this study was obtained from Committee of medical laboratory science, Sudan University of Science and Technology, ethical approval number (MLS - IEC - 08 - 17). Written informed consent for participation and publication of the data was obtained from the all participants included in this study.

\section{Availability of data and materials}

The data are available at https://doi.org/10.6084/m9.figshare.12401675.v1

\section{Funding}

None

\section{Acknowledgments}

Not applicable

Consent for publication

All participantS were informed for publication of data.

\section{Competing interests}

The authors declare that they have no competing interests.

\section{Authors' contributions}

$\mathrm{AlH}$ and YFH designed the study, JOA, EAA, performed the experiments, HNA and ABA analyzed the data, $\mathrm{ABA}$ and $\mathrm{AlH}$ wrote the manuscript, all the authors approved the final version of the manuscript. 


\section{References}

1. World Health Organization. Global status report on noncommunicable diseases 2014. World.

2. Health 0. 2014.

3. Anonymous. (2014). The health consequences of smoking-50 years of progress: a report of.

4. th e surgeon general. U.S. Department of Health and Human Services Centres for Disease.

5. National Centre for Chronic Disease Prevention and Health Promotion

Control, Prevention. National Centre for Chronic Disease Prevention and Health Promotion.

6. Office on Smoking. and Health, Atlanta, GA. Available at http:\\pubMed [accessed at 20, Jul.

7. 2018.

8. 3. Oberg, M., Jaakkola, MS., Woodward, A., Peruga, A. and Pruss-Ustun, A. (2011).Worldwide

9. burden of disease from exposure to second-hand smoke: a retrospective analysis of data from

10. 192. countries. Lancet. 377: 139-146.

11. 4. Stampfli, MR., Anderson, GP. (2009). How cigarette smoke skews immune responses to

12. promote infection, lung disease and cancer. Nat. Rev. Immunol. 9(5):377-384.

13. 5. Prasad, DS., Kabir, Z., Dash, AK., Das, BC. (2009). Smoking and cardiovascular health: a review of the epidemiology, pathogenesis, prevention and control of tobacco.Indian J. Med. Sci.

14. 63. (11):520-533.

15. 6. Yao, H., Rahman, I. (2011). Current concepts on oxidative/carbonyl stress, inflammation and

16. epigenetic in pathogenesis of chronic obstructive pulmonary disease. Toxicol. Appl.

17. Pharmacol. 254(2):72-85.

18. 7. Pryor, WA., Stone, K., Zang, LY., Bermudez, E. (1998). Fractionation of aqueous cigarette tar

19. extracts: fractions that contain the tar radical cause DNA damage. Chem. Res. Toxicol.11(5):

20. 441. -448 .

21. 8. Feng, Y., Kang, Y., (2011). Exposure to cigarette smoke inhibits the pulmonary T-cell response

22. to influenza virus and Mycobacterium tuberculosis. Infect. Immun. 79:229-237.

23. 9. Huvenne, W., Ellen, A., Lanckacker, Olga Krysko, Ken R Bracke, Tine Demoor,Peter W Hellings, Guy G Brusselle, Guy F Joos, Claus Bachert, and Tania Maes, (2011). Exacerbation of cigarette smokeinduced pulmonary inflammation by Staphylococcus aureus enterotoxin B in

24. mice. Respir Res. 12(1): 69.

25. 10. Yageta, Y., Ishii, Y., Morishima, Y., Masuko, H., Ano, S., Tadahiro Yamadori,Ken Itoh, Kaoru Takeuchi, Masayuki Yamamoto, and Nobuyuki Hizawa. (2011). Role of Nrf2 in host defense against influenza virus in cigarette smoke-exposed mice. J. Virol.85(10):4679-4690.

26. 11. Kulkarni, R., Rampersaud, R., Aguilar, LJ., Randis, MT., Kreindler, LJ., and Ratner,JA.

27. 2010. Cigarette smoke inhibits airway epithelial cell innate immune responses to

28. bacteria. Infect. Immun. 78(5):2146-2152. 
29. 12. Garmendia, J., Morey, P. and Bengoechea, JA. (2012). Impact of cigarette smoke exposure 30. on host-bacterial pathogen interactions. Eur Respir J. 39:467-477.

31. 13. American Lung Association. (2011). Hookah Smoking: A Growing Threat to Public 32. Health Issue Brief... Smoke free Communities Project, [accessed 2015 Sep 14].

33. 14. Yadav S, Rawal G. Waterpipe tobacco smoking: A mini-review. Journal of translational 34. internal medicine. 2018 Dec;6(4):173.

35. 15. Cobb, CO., Ward, KD., Maziak, W., Shihadeh, AL., Eissenberg, T.(2010). Waterpipe Tobacco 36. Smoking an Emerging Health Crisis in the United States. Americ J. Health. Behavior.

37. 34. (3):275-285.

38. 16. Durai, R., Ng, PC. and Hoque, H.(2010). Methicillin-resistant Staphylococcus aureus:an 39. update. AORN J 91(5):99-606.

40. 17. Kristiansen MM, Leandro C, Ordway D, Martins M, Viveiros M, Pacheco T, Kristiansen JE, 41. Amaral L. Phenothiazines alter resistance of methicillin-resistant strains of Staphylococcus 42. aureus (MRSA) to oxacillin in vitro. International journal of antimicrobial agents.2003 Sep 43. 1.;22(3):250-3.

44. 18. Porto, JP. Santos, RO., Gontijo, Filho, PP. and Ribas, RM. (2013). Active surveillance to 45. determine the impact of methicillin resistance on mortality in patients with bacteraemia and 46. influences of the use of antibiotics on the development of MRSA infection. Rev Soc Brasil Med 47. Trop 46(6):713-718.

48. 19. Belkaid $Y$, Hand TW. Role of the microbiota in immunity and inflammation. Cell.2014 Mar 49. 27.;157(1):121 - 41.

50. 20. Durmaz, R., Tekerekoglu, MS., Kalcioglu, T. and Ozturan, O. (2001). Nasal carriage of 51. methicillin-resistant Staphylococcus aureus among smokers and cigarette factory workers.New Microbial24:143-147.

52. 21. Brook, l., and Hausfeld, JN.(2011). Microbiology of acute and chronic maxillary sinusitis in 53. smokers and non-smokers. Ann Otol Rhinol Laryngol. 120(11):707-712.

54. 22. Stepanović S, Djukić V, Djordjević V, Djukić S. Influence of the incubation atmosphere on the production of biofilm by staphylococci. Clinical microbiology and infection.2003 Sep;9(9):955-8.

55. 23. Carr FJ. Microbiology: A fundamental introduction. EC Microbiology. 2017;8(3):123 - 83.

56. 24. Lodise TP, Graves J, Evans A, Graffunder E, Helmecke M, Lomaestro BM, Stellrecht K.

57. Relationship between vancomycin MIC and failure among patients with MRSA bacteremia 58. treated with vancomycin. Antimicrobial Agents and Chemotherapy. 2008 Jun 30.

59. 25. Lee DK, Kim YN, Park KS, Yang JW, Kim KJ, Ha NJ. Antimicrobial activity of mupirocin, 60. daptomycin, linezolid, quinupristin/dalfopristin and tigecycline against vancomycin-resistant 61. enterococci (VRE) from clinical isolates in Korea (1998 and 2005). BMB Reports. 2007;40(6):881-7. 
62. 26. Saravolatz LD, Pawlak J, Johnson L, Bonilla H, Fakih MG, Fugelli A, Olsen WM.In vitro

63. activities of LTX-109, a synthetic antimicrobial peptide, against methicillin-resistant,vancomycinintermediate, vancomycin-resistant, daptomycin-nonsusceptible, and linezolid-

64. nonsusceptible Staphylococcus aureus. Antimicrobial agents and chemotherapy. 2012 Aug 65. 1.;56(8):4478-82.

66. 27. Cheasbrough, M., (2012). District Laboratory practice in Tropical Countries part 2. Second 67. Ed. New York. Cambridge University press.157-158, 238, 239, 400-402.

68. 28. Clinical Laboratory Standards Institute (2014). Interpretative charge zone size performs 69. standerds for untimicrobial susceptibility test USA, 27(1): 32-52.

70. 29. Compain, F., Babosan, A., Brisse, S., Genel, N., Audo, J., Ailloud, F., Kassis-Chikhani,N., Arlet, G. and Decre, D. (2014). Multiplex PCR for detection of seven virulence factors and K1/K2

71. capsular serotypes of Klebsiella pneumoniae. J. Clinical Microbiol. 52(12):4377-4380.

72. 30. Sambrook, J., Fritsch, E.F. and Maniatis, T.(1989). Gel electrophoresis of DNA.In: Molecular

73. Cloning: a Laboratory Manual. New York: Cold Spring Harbor Laboratory Press, Cold Spring Harbor, NY,USA.

74. 31. Abdullah, HM., Zaki, WK. and Elnaggar, MK. (2010). Risk of nasal colonization of MRSA in

75. tropical medicine and microbiology. Egyptian J. Medical Microbiol. 19 (2): 95-102

76. 32. Chatterjee, SS., and Ray, P. (2009). Community based study on nasal carrier of

77. Staphylococcus aureus. India J Med Res. 130:742-748.

78. 33. Lu, P.L., Chin, C.F., Peng, Y.H., Chang, T.P. and Chen, L.A. (2005). Risk factors and molecular analysis community acquired methicillin-resistant S.aureus. J. Clin Microbiol.43:

\section{Figures}




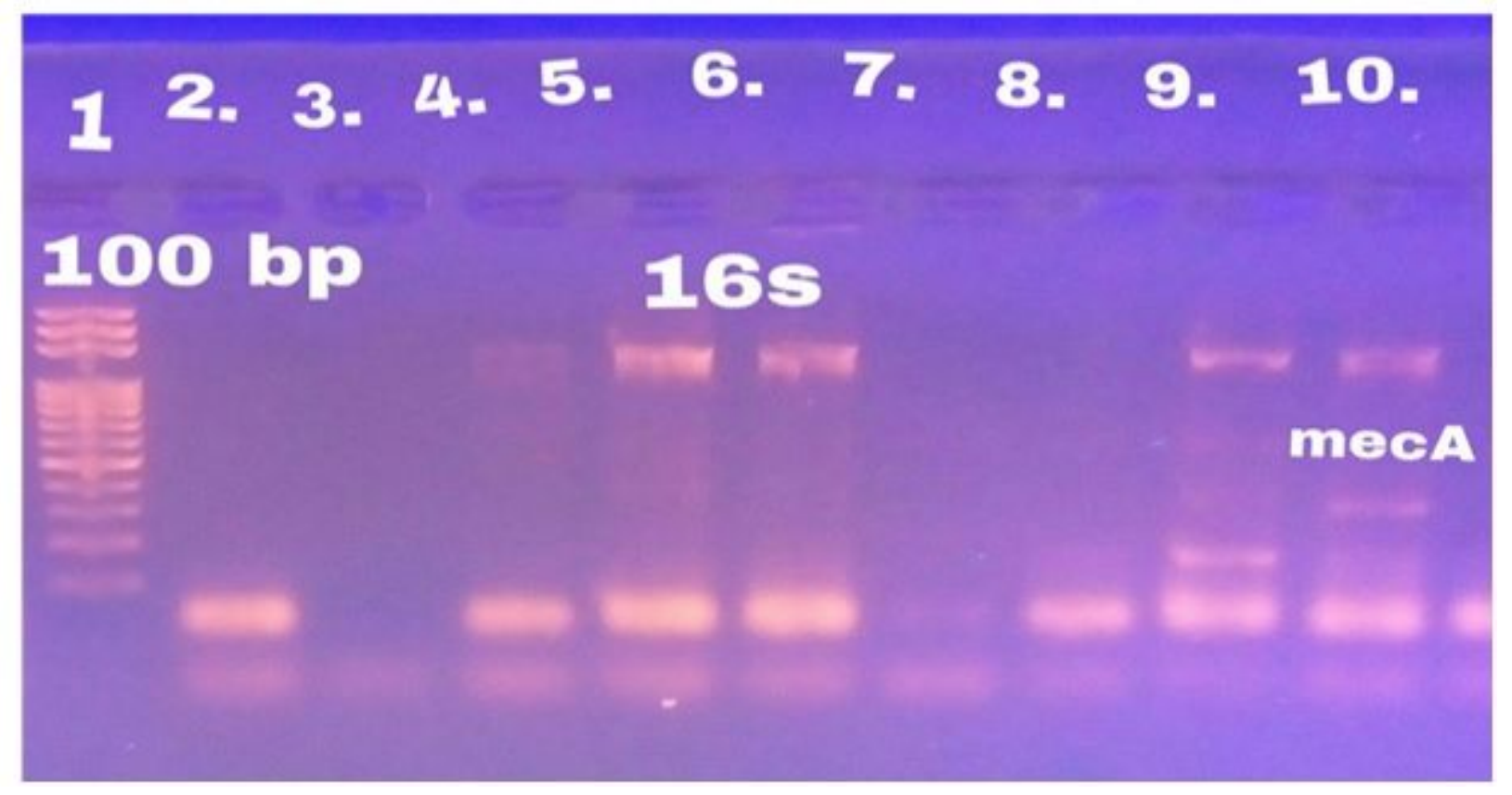

Figure 1

Detection of mecA gene by gel electrophorisis: Lane one is ladder samples $6,7,9$ and 10 show $16 \mathrm{~s}$ rRNA, only sample 10 show mecA positive. 